Perspectiva Geográfica

ISSN 0123-3769

Vol. 15/2010; pp. 239-260

\title{
Organización territorial, desarrollo sostenible y nuevas visiones sobre el territorio en Colombia (1991 2010)
}

Territorial organization, sustainable development

and new views on the territory in Colombia (1991 2010)

Franz Gutiérrez Rey*

\section{Resumen}

El artículo analiza los antecedentes legislativos de la organización territorial en Colombia, desde la promulgación de la Constitución Política de 1991 hasta la propuesta de Ley Orgánica de Ordenamiento Territorial de 2010, para explicar desde una perspectiva geográfica el desarrollo y avance de las políticas sobre ordenamiento territorial, el desarrollo sostenible y la inclusión de nuevas visiones sobre el territorio, como la gobernanza y la cohesión social y territorial, fundamentales hoy por su significado, contenidos y aporte a la organización del territorio.

Palabras clave: Cohesión social y territorial, Constitución política, Desarrollo sostenible, Gobernanza, Ley orgánica de ordenamiento territorial, Ordenamiento territorial, Organización territorial.

Geógrafo, Magíster en Geografía con énfasis en Ordenamiento Territorial. Docente Universidad Pedagógica y Tecnológica de Colombia. Director Grupo de Investigación Ordenamiento Ambiental del Territorio (OAT). franz@geordena.com franz.gutierrez@uptc.edu.co http://www.geordena.com 


\begin{abstract}
This article analyzes the legislative antecedents of the territorial organization in Colombia, from the promulgation of the Political Constitution of 1991to the proposal of Statutory Law of Territorial Ordering of 2010, to explain from a geographical perspective the development and advance of the political ones on territorial ordering, sustainable development and the inclusion of new visions on the territory, such as governance and the social and territorial cohesion, fundamental today by its meaning, contents and contribution to the organization of the territory.

Key words: Social and territorial cohesion, Constitution, Sustainable development, Governance, Statutory Law of Territorial Ordering, Territorial ordering, Territorial organization.
\end{abstract}

240 Franz Gutiérrez Rey 


\section{Introducción}

Desde la proclamación de la Constitución Política de Colombia (CPC) de 1991, hace veinte años, temas como el desarrollo sostenible y el ordenamiento territorial se han superado por medio de leyes ordinarias focales y dispersas, y, en otros casos, utilizando legislación preconstituyente o sentencias de la Corte Constitucional que se han venido estableciendo como derroteros de la organización territorial. Los avances en materia de sostenibilidad territorial se han apoyado en la internacionalización de las relaciones en asuntos ecológicos (principio de la precaución, establecido en la Constitución Política de Colombia, 1991).

A pesar de que los temas de la organización del territorio referidos al desarrollo sostenible, la gobernanza y la cohesión territorial no aparecen desarrollados explícitamente en la legislación colombiana, se coligen en algunas líneas, y en la última propuesta de LOOT (2010) encuentran por primera vez una definición, así sea incipiente, desde el punto de vista académico y técnico.

\section{Constitución Política de Colombia}

La Constitución Política de Colombia (CPC) de 1991 estableció, en cuanto a la organización territorial, un régimen híbrido denominado Estado Unitario Complejo ${ }^{1}$, y en materia de Ordenamiento Territorial (OT) se considera que no fue sistemática ni coherente, al involucrar elementos característicos de tres tipos de Estado: Unitario (Centralista), Federal (Autonomía Territorial) y Regional (Regiones Administrativas de Planificación (RAP), y su conversión a Entidades Territoriales, RET (Eljash, 2010). En su artículo 288, la CPC instituyó la creación de la Ley Orgánica de Ordenamiento Territorial (LOOT), que establecería la distribución de competencias entre la Nación y las entidades territoriales (departamentos, municipios, áreas metropolitanas y distritos), ejercidas conforme a los principios de coordinación, concurrencia y subsidiariedad en los términos que estableciera la Ley (Tabla 1).

A veinte años de proclamada la Constitución Política aún no ha sido posible promulgar la LOOT (se han presentado 21 proyectos fallidos, lo que equivale a más de un proyecto por año); pero sí se han modificado veintinueve veces, en actos legislativos, artículos de la CPC que afectan el régimen territorial (299 -elección de diputados-, 356 y 357 -sistema general de participaciones de los departamentos, distritos y municipios-, 55 -comunidades negras-, entre otros), y se crearon seis distritos nuevos, cinco de los cuales la Corte Constitucional declaró inexequibles, quedando únicamente el Distrito Especial Portuario, Biodiverso y Ecoturístico de

Los Estados Unitarios Complejos permiten tan solo la descentralización administrativa, pues, en un plano político, la descentralización constitucional o legislativa los llevaría a una forma política federal o regional (Ferrando, 2005). 
Buenaventura, en el departamento del Valle del Cauca, el cual sigue funcionando como municipio.

Se estima que la promulgación de la LOOT no ha sido posible en razón a tres factores: voluntad política, interés en la dimensión regional del ordenamiento territorial y el gran número de normas sobre la materia, que implica en muchas ocasiones un desconocimiento del tema (Carrión Barrero, 2008). Este último aspecto es tratado a continuación.

Al no existir la LOOT, con el tiempo quedaron sin perfeccionamiento artículos claves de la CPC para los procesos de Ordenamiento Territorial, como el 288 -distribución de competencias entre la Nación y las entidades territoriales-, el 297 -formación de nuevos departamentos-, el 307 -conversión de Región en entidad territorial-, el 319 -establecimiento del régimen administrativo y fiscal de carácter especial para las áreas metropolitanas- y el 329 -conformación de las Entidades Territoriales Indígenas, ETIS-, entre otros más (Tabla 1). Así mismo, el artículo transitorio 38, sobre la conformación de la Comisión de Ordenamiento Territorial (COT), encargada de realizar los estudios y formular ante las autoridades competentes las recomendaciones que considerara del caso para acomodar la división territorial del país a las disposiciones de la Constitución Política, tampoco ha incidido en cambio alguno sobre el particular (Tabla 1).

Tabla 1. Artículos de la Constitución Política de Colombia (1991) sobre Ordenamiento Territorial

\begin{tabular}{|c|l|}
\hline \multicolumn{1}{|c|}{ ARTÍCULO } & \multicolumn{1}{c|}{ TEMA } \\
\hline ARTÍCULO 285 & $\begin{array}{l}\text { Fuera de la división general del territorio, habrá las que determine la ley para el } \\
\text { cumplimiento de las funciones y servicios a cargo del Estado. }\end{array}$ \\
\hline ARTÍCULO 286 & $\begin{array}{l}\text { Son entidades territoriales los departamentos, los distritos, los municipios y los } \\
\text { territorios indígenas. La ley podrá darles el carácter de entidades territoriales a } \\
\text { las regiones y provincias que se constituyan en los términos de la Constitución y } \\
\text { de la ley. }\end{array}$ \\
\hline ARTÍCULO 288 & $\begin{array}{l}\text { La Ley Orgánica de Ordenamiento Territorial establecerá la distribución de } \\
\text { competencias entre la Nación y las entidades territoriales. Las competencias } \\
\text { atribuidas a los distintos niveles territoriales serán ejercidas conforme a los } \\
\text { principios de coordinación, concurrencia y subsidiariedad en los términos que } \\
\text { establezca la ley. }\end{array}$ \\
\hline ARTÍCULO 297 & $\begin{array}{l}\text { El Congreso Nacional puede decretar la formación de nuevos departamentos, } \\
\text { siempre que se cumplan los requisitos exigidos en la Ley Orgánica del } \\
\text { Ordenamiento Territorial y una vez verificados los procedimientos, estudios y } \\
\text { consulta popular dispuestos por esta Constitución. }\end{array}$ \\
\hline ARTÍCULO 302 & $\begin{array}{l}\text { La ley podrá establecer para uno o varios departamentos diversas capacidades } \\
\text { y competencias de gestión administrativa y fiscal distintas a las señaladas para } \\
\text { ellos en la Constitución, en atención a la necesidad de mejorar la administración }\end{array}$ \\
\hline
\end{tabular}




\begin{tabular}{|c|c|}
\hline ARTÍCULO & TEMA \\
\hline ARTÍCULO 302 & $\begin{array}{l}\text { o la prestación de los servicios públicos de acuerdo con su población, recursos } \\
\text { económicos y naturales y circunstancias sociales, culturales y ecológicas. En } \\
\text { desarrollo de lo anterior, la ley podrá delegar, a uno o varios departamentos, } \\
\text { atribuciones propias de los organismos o entidades públicas nacionales. }\end{array}$ \\
\hline ARTÍCULO 306 & $\begin{array}{l}\text { Dos o más departamentos podrán constituirse en regiones administrativas y de } \\
\text { planificación, con personería jurídica, autonomía y patrimonio propio. Su objeto } \\
\text { principal será el desarrollo económico y social del respectivo territorio. }\end{array}$ \\
\hline ARTÍCULO 307 & $\begin{array}{l}\text { La respectiva Ley Orgánica, previo concepto de la Comisión de Ordenamiento } \\
\text { Territorial, establecerá las condiciones para solicitar la conversión de la Región } \\
\text { en entidad territorial. La decisión tomada por el Congreso se someterá en cada } \\
\text { caso a referendo de los ciudadanos de los departamentos interesados. La misma } \\
\text { Ley establecerá las atribuciones, los órganos de administración, y los recursos } \\
\text { de las regiones y su participación en el manejo de los ingresos provenientes del } \\
\text { Fondo Nacional de Regalías. Igualmente definirá los principios para la adopción } \\
\text { del estatuto especial de cada región. }\end{array}$ \\
\hline ARTÍCULO 319 & $\begin{array}{l}\text { Cuando dos o más municipios tengan relaciones económicas, sociales y físicas } \\
\text { que den al conjunto características de un área metropolitana, podrán organizarse } \\
\text { como entidad administrativa encargada de programar y coordinar el desarrollo } \\
\text { armónico e integrado del territorio colocado bajo su autoridad; racionalizar la } \\
\text { prestación de los servicios públicos a cargo de quienes la integran y, si es el caso, } \\
\text { prestar en común algunos de ellos; y ejecutar obras de interés metropolitano. La } \\
\text { Ley de Ordenamiento Territorial adoptará para las áreas metropolitanas un } \\
\text { régimen administrativo y fiscal de carácter especial; garantizará que en sus } \\
\text { órganos de administración tengan adecuada participación las respectivas } \\
\text { autoridades municipales; y señalará la forma de convocar y realizar las consultas } \\
\text { populares que decidan la vinculación de los municipios. }\end{array}$ \\
\hline ARTÍCULO 320 & $\begin{array}{l}\text { La ley podrá establecer categorías de municipios de acuerdo con su población, } \\
\text { recursos fiscales, importancia económica y situación geográfica, y señalar distinto } \\
\text { régimen para su organización, gobierno y administración. }\end{array}$ \\
\hline ARTÍCULO 325 & $\begin{array}{l}\text { Con el fin de garantizar la ejecución de planes y programas de desarrollo integral } \\
\text { y la prestación oportuna y eficiente de los servicios a su cargo, dentro de las } \\
\text { condiciones que fijen la Constitución y la ley, el Distrito Capital podrá conformar } \\
\text { un área metropolitana con los municipios circunvecinos y una región con otras } \\
\text { entidades territoriales de carácter departamental. }\end{array}$ \\
\hline ARTÍCULO 326 & $\begin{array}{l}\text { Los municipios circunvecinos podrán incorporarse al Distrito Capital si así lo lo } \\
\text { determinan los ciudadanos que residan en ellos mediante votación que tendrá } \\
\text { lugar cuando el concejo distrital haya manifestado su acuerdo con esta vinculación. } \\
\text { Si ésta ocurre, al antiguo municipio se le aplicarán las normas constitucionales y } \\
\text { legales vigentes para las demás localidades que conformen el Distrito Capital. }\end{array}$ \\
\hline ARTÍCULO 329 & $\begin{array}{l}\text { La conformación de las Entidades Territoriales Indígenas se hará con sujeción a } \\
\text { lo dispuesto en la Ley Orgánica de Ordenamiento Territorial, y su delimitación } \\
\text { se hará por el Gobierno Nacional, con participación de los representantes de las } \\
\text { comunidades indígenas, previo concepto de la Comisión de Ordenamiento } \\
\text { Territorial. }\end{array}$ \\
\hline ARTÍCULO 334 & $\begin{array}{l}\text { La dirección general de la economía estará a cargo del Estado. Este intervendrá, } \\
\text { por mandato de la ley, en la explotación de los recursos naturales, en el uso del }\end{array}$ \\
\hline
\end{tabular}

Perspect. geogr. Vol. 15. Año 2010, pp. 239-260 243 


\begin{tabular}{|c|l|}
\hline ARTICULO & \multicolumn{1}{c|}{ TEMA } \\
\hline ARTÍCULO 334 & $\begin{array}{l}\text { suelo, en la producción, distribución, utilización y consumo de los bienes, y en } \\
\text { los servicios públicos y privados, para racionalizar la economía con el fin de } \\
\text { conseguir el mejoramiento de la calidad de vida de los habitantes, la distribución } \\
\text { equitiva de las oportunidades y los beneficios del desarrollo y la preservación } \\
\text { de umbiente sano. } \\
\text { El Estado, de manera especial, intervendrá para dar pleno empleo a los recursos } \\
\text { humanos y asegurar que todas las personas, en particular las de menores ingresos, } \\
\text { tengan acceso efectivo a los bienes y servicios básicos. } \\
\text { También para promover la productividad y la competitividad y el desarrollo } \\
\text { armónico de las regiones. }\end{array}$ \\
\hline ARTÍCULO 361 & $\begin{array}{l}\text { Con los ingresos provenientes de las regalías que no sean asignados a los } \\
\text { departamentos y municipios, se creará un fondo nacional de regalías cuyos } \\
\text { recursos se destinarán a las entidades territoriales en los términos que señale la } \\
\text { ley. Estos fondos se aplicarán a la promoción de la minería, a la preservación del } \\
\text { ambiente y a financiar proyectos regionales de inversión definidos como } \\
\text { prioritarios en los planes de desarrollo de las respectivas entidades territoriales. }\end{array}$ \\
\hline $\begin{array}{c}\text { ARTÍCULO 38 } \\
\text { (TRANSITORIO) }\end{array}$ & $\begin{array}{l}\text { El Gobierno organizará e integrará, en el término de seis meses, una Comisión } \\
\text { de OT, encargada de realizar los estudios y formular ante las autoridades } \\
\text { competentes las recomendaciones que considere del caso para acomodar la división } \\
\text { territorial del país a las disposiciones de la Constitución. La Comisión cumplirá } \\
\text { sus funciones durante un período de tres años, pero la ley podrá darle carácter } \\
\text { permanente. En este caso, la misma ley fijará la periodicidad con la cual presentará } \\
\text { sus propuestas. }\end{array}$ \\
\hline
\end{tabular}

Fuente: Constitución Política de Colombia, 1991.

De acuerdo con Eljach (2007), de todos los elementos del territorio (suelo, subsuelo, espacio aéreo, mar territorial, etc.), la CPC se aplicó a la superficie terrestre (zona continental), desconociendo otros elementos que integran el territorio, y sobre el OT se dirigió a la Organización Político-Administrativa, dejando de lado lo ambiental, económico, social y territorial. La división Político-Administrativa (anterior y actual) asimila los espacios políticos de Entidad Territorial y circunscripción electoral como si siempre debieran coincidir o seguir la misma suerte. Hoy la Constitución no es la misma de 1991, ni el Estado, ni la sociedad; sin embargo, el régimen territorial políticoadministrativo sigue manejándose igual que el establecido en la Constitución de 1886.

\section{Legislación preconstituyente}

En algunos asuntos trascendentales se siguen aplicando leyes preconstituyentes, como el Decreto Ley 1222 de 1986 -Código de Régimen Departamental-, el Decreto Ley 1333 de 1986 parcial -Código de Régimen Municipal-, la Ley 10 de 1978 -Normas sobre mar territorial, zona económica exclusiva, plataforma continental y otras disposiciones-, la Ley 12 de 1983 -Comunidades Autónomas- y la Ley 9 de 1989 -Reforma urbana-. 


\section{Corte Constitucional}

Ante el vacío legislativo de la CPC, la Corte Constitucional ha venido estableciendo los derroteros del proceso de organización territorial, operando como legislador complementario (concepto de autonomía, descentralización, legislación orgánica, reserva de ley, áreas de manejo especial, entre otros). Sin embargo, se ha avanzado sectorialmente en temas como: Plan de Ordenamiento Territorial (POT), Ordenamiento de Cuencas Hidrográficas (Decreto Ley 1729 de 2002), Áreas Metropolitanas y Distritos, reparto de competencias administrativas y endeudamiento de las entidades territoriales, entre otros; aunque por mandato constitucional expreso, a veces en forma no técnica, algunos temas están petrificados al tipo de legislación orgánica, aun tratándose de temas accesorios o no esenciales (no orgánicos). En conclusión, la jurisprudencia ha permitido que la legislación sobre asuntos territoriales se expida fragmentariamente y no en una única LOOT (Sentencia Corte Constitucional 600A/95 y C-1042/07).

\section{Propuestas para la Ley Orgánica de OT}

Plantea Eljach (2010) que a partir del texto constitucional, de la doctrina nacional y extranjera, de la jurisprudencia interna y de la praxis legislativa ocurrida hasta ahora, se deduce que no es conveniente ni oportuno reunir todo el régimen jurídico de la organización territorial del Estado en una única LOOT, en razón a que está integrado por normas constitucionales (dogmáticas y orgánicas) y diversos tipos de leyes (orgánicas y ordinarias) y reglamentos administrativos, y que además está incompleto.

De análisis como el anterior se coligen algunas propuestas de legislación para el mejoramiento de la organización territorial del país y de la LOOT a nivel constitucional, orgánico y ordinario, las cuales se enuncian en la Tabla 2. 
Tabla 2. Propuestas de acciones sobre la legislación en el marco de la organización territorial y la LOOT en Colombia

\begin{tabular}{|c|c|}
\hline NIVEL & PROPUESTAS DE ACCIÓN \\
\hline CONSTITUCIONAL & $\begin{array}{l}\text { - Definir claramente el tipo de Estado por construir en lo territorial (unitario-descentralizado, } \\
\text { federal, regional o un híbrido entre estos). } \\
\text { - Concretar las modalidades de entidades territoriales locales (municipios, distritos, } \\
\text { entidades territoriales indígenas -ETIS-), intermedias (solo departamentos), y las demás } \\
\text { escalas tomarlas como unidades de planificación y gestión (artículos } 285 \text { y } 286 \text { CPC, } \\
\text { Tabla 1). } \\
\text { - Promover decidida y sostenidamente el desarrollo legal y el ejercicio de la autonomía en } \\
\text { lo territorial. } \\
\text { - No reducir la relación Estado central-entidades territoriales a la descentralización, sobre } \\
\text { la que ya se ha venido avanzando en la modalidad de focalización de recursos fiscales y } \\
\text { desconcentración. } \\
\text { - Modificar los artículos } 306 \text { y } 307 \text { para permitir que las regiones se puedan constituir con } \\
\text { departamentos completos o porción de ellos (Tabla 1). } \\
\text { - Creación de un fondo especial de desarrollo territorial para destinarlo a la construcción } \\
\text { de infraestructura nacional (vías, puertos, aeropuertos, telecomunicaciones, etc.), por } \\
\text { regiones (artículos } 334 \text { y } 361 \text {, Tabla 1) y no por circunscripciones electorales o territoriales, } \\
\text { procurando equidad de la inversión. }\end{array}$ \\
\hline ORGÁNICO & $\begin{array}{l}\text { - Toda la legislación de tipo orgánico ya expedida sobre temas específicos de ordenamiento } \\
\text { territorial (leyes } 128,715,768,1076) \text {, con sus respectivos ajustes, y concordados con } \\
\text { algunas estatutarias }(134,137) \text {. } \\
\text { - Normativa sobre autonomía, principios constitucionales de coordinación, concurrencia y } \\
\text { subsidiariedad, desarrollo de los derechos y garantías institucionales de rango constitucional } \\
\text { que protegen a las entidades territoriales (competencias territoriales). } \\
\text { - Todos los temas que, mediante el método de interpretación axiológico, sistemático, } \\
\text { histórico y finalístico, se concluya corresponden al tipo de ley orgánica (conexidad } \\
\text { inescindible con el núcleo esencial de la norma). } \\
\text { - Desarrollo de los mandatos constitucionales de los artículos } 302 \text { y } 320 \text { (Tabla 1). Criterios } \\
\text { de flexibilidad, gradualidad, asociatividad, diversidad de regímenes. } \\
\text { - Institucionalidad eficiente y eficaz ("con músculos" o "con dientes" coercitivos) para la } \\
\text { gestión legislativa y el control político del ordenamiento territorial (COT, 1993). }\end{array}$ \\
\hline ORDINARIO & $\begin{array}{l}\text { - Nuevo régimen departamental (Proyecto de Ley } 019 \text { de 2008); regiones administrativas y } \\
\text { de planificación; provincias administrativas y territoriales y ajustes al régimen municipal. } \\
\text { - Definición legal de la estructura organizativa mediante la cual el Gobierno Central } \\
\text { (Ministerios) ejercerá las funciones de cancillería del interior (relaciones entre el Gobierno } \\
\text { Central y las Entidades Territoriales sobre la base de los principios de descentralización } \\
\text { integral y autonomía territorial, concurrencia, coordinación y subsidiaridad). } \\
\text { - Reasignación de algunas competencias actualmente a cargo de organismos centrales a } \\
\text { entidades territoriales (departamentos, distritos y capitales), Superintendencias y } \\
\text { Corporaciones Autónomas Regionales (CAR). } \\
\text { - Verdadera descentralización y delegación de competencias y recursos. } \\
\text { - Modernización del régimen catastral y del impuesto predial, particularmente. } \\
\text { - Modernización del Régimen Tributario de las Entidades Territoriales. } \\
\text { - Modernización de las normas sobre revisión de límites, solución de conflictos limítrofes } \\
\text { y publicación del mapa oficial (Proyecto de Ley } 210 \text { de } 2003 \text {, } 135 \text { y } 155 \text { de } 2008 \text { Senado). } \\
\text { - Legislación sobre mar territorial, plataforma submarina, lecho marino y especies } \\
\text { náufragas, áreas costeras del territorio continental y regiones insulares. }\end{array}$ \\
\hline
\end{tabular}

Fuentes: Carrión (2008); DNP (2010); Eljach (2010); Ladino (2008). 


\section{Desarrollo territorial y desarrollo sostenible}

Gran parte de las bases legales del ordenamiento y de la ordenación del territorio $^{2}$ se encuentra en la Ley de Desarrollo Territorial 388, de 1997, la cual estableció para el país, en su artículo segundo, tres principios rectores en que se fundamenta el ordenamiento del territorio: la función social y ecológica de la propiedad ${ }^{3}$, la prevalencia del interés general sobre el particular y la distribución equitativa de las cargas y los beneficios, principios que no han sido suficientes para desarrollar una política de Ordenamiento Territorial (OT) y Desarrollo Sostenible (DS), y que en realidad hacen parte del ejercicio de competencias entre los diferentes entes territoriales, como se plantea en el nuevo proyecto de LOOT, $2010^{4}$.

De acuerdo con Carrión Barrero (2008), la Ley 388 de 1997 se ha criticado en la aplicación práctica y formulación de los planes de ordenamiento territorial con tres argumentos: la debilidad técnica de los POT formulados, el ámbito municipal de la Ley y el énfasis urbano de los instrumentos por desarrollar en dichos Planes de Ordenamiento Territorial.

Respecto al tema del Desarrollo Sostenible, en la Constitución Política de 1991, en el artículo 80, se enuncia que

El Estado planificará el manejo y aprovechamiento de los recursos naturales, para garantizar su desarrollo sostenible, su conservación, restauración o sustitución. Además, deberá prevenir y controlar los factores de deterioro ambiental, imponer las sanciones legales y exigir la reparación de los daños causados. Así mismo, cooperará con otras naciones en la protección de los ecosistemas situados en las zonas fronterizas.

Lo anterior muestra que no hay una directriz clara desde la CPC sobre el tipo de desarrollo que se busca o quiere, aparte del crecimiento económico; el principio de desarrollo sostenible concebido está basado en el "manejo y aprovechamiento de los recursos naturales" y no desde el equilibrio entre lo económico, social, ambiental y territorial o la territorialización del desarrollo. También es frecuente encontrar en textos construcciones

En el presente documento el término ordenamiento territorial se entiende como la política y normativa, con fuerza de ley, que regula el uso del territorio, ya sea el país como un todo o una división político administrativa de él, y la expresión ordenación del territorio, como el proceso y la técnica para llegar a dicha normativa (aplicación).

3 La función ecológica de la propiedad se plantea en el Artículo 58 de la Constitución Política ("La propiedad es una función social que implica obligaciones. Como tal, le es inherente una función ecológica"); la jurisprudencia y la doctrina lo han entendido como elemento necesario para garantizar el desarrollo sostenible (Rodríguez, 2004). Así, la función ecológica implica un deber cualificado de protección (Corte Constitucional, Sentencia T - 294 de 2004) que tiene una triple dimensión: en primer lugar, la protección al medio ambiente es un principio que irradia todo el orden jurídico, pues es obligación del Estado proteger las riquezas naturales de la Nación; en segundo lugar, aparece como el derecho de todas las personas a gozar de un ambiente sano, derecho constitucional que es exigible por diversas vías judiciales, y, finalmente, de esta función social se derivan un conjunto de obligaciones impuestas a las autoridades y a los particulares (Corte Constitucional, Sentencia T-760 del 25 de 2007).

4 Son principios rectores del ejercicio de competencias: coordinación, concurrencia, subsidiariedad, complementariedad, eficiencia, equilibrio entre competencias y recursos, gradualidad y responsabilidad. 
teóricas o interpretaciones que aprovechan estos vacíos legislativos para interpretar el Desarrollo Sostenible como norma constitucional o propósito nacional, sin estar reglamentado:

...al respecto, la Constitución Política de 1991 cobija el término Desarrollo Sostenible "como los derechos brindados a los ciudadanos para actuar en favor de la protección ambiental, planteando un equilibrio entre los modelos socioeconómicos del país y el cuidado del medio ambiente, creando además una conciencia empresarial que rechaza el asumir los altos costos de producción y las tasas, antes que invertir en tecnologías limpias. El Desarrollo Sostenible es en Colombia una norma constitucional y, por consiguiente, un imperativo para las empresas (Clase Empresarial, 1997: 94, citada en Barrios de Caputo 1996).

Otros, como Martínez (2005), sostienen que en Colombia a partir de la Constitución Politica de 1991 se asume el desarrollo sostenible como un propósito nacional y se señala la obligación del Estado de emprender acciones en tal dirección, lo cual supone un cambio en el modelo actual de desarrollo; sin embargo, esto, parece ser, ha quedado como una simple intención. ¿Pero de dónde proviene esta afirmación?

El desarrollo y los avances del orden constitucional en materia ambiental y de sostenibilidad parten de los desarrollos legislativos anteriores a la constitución de 1991, y desde la Constitución se han apoyado en el artículo 226 sobre la internacionalización de las relaciones en asuntos ecológicos (Principio de la Precaución): “El Estado promoverá la internacionalización de las relaciones políticas, económicas, sociales y ecológicas sobre bases de equidad, reciprocidad y conveniencia nacional". Así se enfatiza la importancia de los diversos instrumentos internacionales para la protección del medioambiente, su concepción de ecosistema y causa global.

Basado en lo anterior, la Ley 99 de 1993 , del medioambiente, hizo alusión expresa a los principios contenidos en la Declaración de Río de Janeiro, 1992, en el artículo $1^{\circ}$, numeral 1 :

La política ambiental colombiana seguirá los siguientes principios generales:

El proceso de desarrollo económico y social del país se orientará según principios universales y del desarrollo sostenible contenidos en la Declaración de Río de Janeiro de 1992 sobre el medio ambiente y desarrollo.

En este sentido y en armonía con lo que estaba ocurriendo en los años noventa respecto del medioambiente, se aprueba con la Ley 164 de 1994 la Convención Marco de las Naciones Unidas sobre el cambio climático, realizada en Nueva York en mayo de 1992, Sentencia Corte Constitucional C-073-95 (García, 2003).

\section{Proyecto de Loot, 2010}

El último Proyecto de Ley Orgánica de Ordenamiento Territorial, LOOT (2010), radicado propone establecer dieciséis 
principios: soberanía y unidad nacional; autonomía; descentralización; integración; regionalización; sostenibilidad; participación; solidaridad y equidad territorial; diversidad; gradualidad y flexibilidad; prospectiva, paz y convivencia; asociatividad, equidad social y equilibrio territorial; economía y buen gobierno (Tabla 3 ).

En la propuesta de LOOT se encuentran avances en materia de visión de país, del desarrollo sostenible y sobre la ordenación del territorio en los principios de soberanía y unidad nacional, donde se definiría el tipo de Estado (Tabla 2 Constitucional-); autonomía y descentralización (las dos anteriores permitirían el desarrollo endógeno y a la vez el regional); regionalización (se esperaba aún más en su desarrollo, Tabla 2 -Constitucional-); sostenibilidad (aparece por primera vez el concepto, aunque se esperaba la introducción en este del concepto de equilibrio entre lo social, lo económico, lo ambiental y lo territorial; el concepto de sostenibilidad fiscal no aplicaría a todas las regiones culturales); participación (muy importante a pesar de que ya se ha desarrollado en otras leyes); solidaridad y equidad territorial (significaría un avance frente a los principios establecidos anteriormente de coordinación, concurrencia y subsidiariedad, Tabla 1 y 2 -Orgánico-); diversidad (reconocimiento tácito en la ley de las diferencias, es un principio de paz, pero aun así es necesaria la ley de ETIS y otras, Tabla 2 -Constitucional-); gradualidad y flexibilidad (reconocimiento de las diferencias en el desarrollo, Tabla 2 -Orgánica-); prospectiva, paz y convivencia (implícito en todos y explícito aquí); asociatividad (necesario para el desarrollo); equidad social y equilibrio territorial (tema esperado y logrado en la propuesta); economía y buen gobierno (en hora buena, véase DS, Gobernanza y Cohesión Territorial).

El proyecto de LOOT presentado a consideración del Congreso de la República define un producto que recopila una larga experiencia; propone, a mi juicio, un significativo avance sobre la opción de organización territorial del Estado, el mejoramiento de la orientación en la participación ciudadana, la convivencia pacífica, la vigencia de un orden justo y el crecimiento socioeconómico equitativo; plantea alianzas estratégicas y promueve la capacidad de negociación entre la Nación y las entidades territoriales a través de propósitos estratégicos, validando los principios rectores del ejercicio de competencias propuestos en la CPC, pero ya no como del OT en general; involucra el concepto de "Buen Gobierno" respecto a la Comisión de Ordenamiento Territorial (COT) busca su consolidación como órgano meramente técnico y de consulta del Gobierno y el Congreso.

De otra parte, existe la intención de que los demás temas concordantes con el

5 Una política de "Buen Gobierno" facilita el cumplimiento de los fines esenciales: servir a la comunidad, promover la prosperidad general y garantizar la eficiencia de los principios, derechos y deberes consagrados en nuestra constitución (Vargas, 2010). 
Ordenamiento Territorial corresponden a leyes ordinarias que desarrollarían los criterios de la política legislativa señalados en el Proyecto de Ley, como la expedición del nuevo Régimen Departamental y la actualización del municipal (Tabla 2 Ordinario-).

Tabla 3. Principios del OT, Proyecto de Ley Orgánica 058 de 2010

\begin{tabular}{|c|c|}
\hline PRINCIPIO & TESIS \\
\hline $\begin{array}{l}\text { SOBERANÍA Y } \\
\text { UNIDAD NACIONAL }\end{array}$ & $\begin{array}{l}\text { El ordenamiento territorial propiciará la integridad territorial, su seguridad y defensa, } \\
\text { y fortalecerá el Estado social de Derecho organizado en forma de República unitaria, } \\
\text { descentralizada y con autonomía de sus entidades territoriales. }\end{array}$ \\
\hline AUTONOMÍA & $\begin{array}{l}\text { Las entidades territoriales gozan de autonomía para la gestión de sus intereses } \\
\text { dentro de los límites de la Constitución y la ley. }\end{array}$ \\
\hline DESCENTRALIZACIÓN & $\begin{array}{l}\text { La distribución de competencias entre la Nación y las entidades territoriales se } \\
\text { realizará trasladando el correspondiente poder de decisión de los órganos centrales } \\
\text { del Estado hacia el nivel territorial pertinente, en lo que corresponda, de tal manera } \\
\text { que se promueva una mayor capacidad de gestión y de administración de sus propios } \\
\text { intereses. }\end{array}$ \\
\hline INTEGRACIÓN & $\begin{array}{l}\text { Los departamentos y los municipios ubicados en zonas fronterizas pueden adelantar } \\
\text { programas de cooperación dirigidos al fomento del desarrollo comunitario, la } \\
\text { prestación de los servicios públicos y la preservación del ambiente con entidades } \\
\text { territoriales limítrofes de un país vecino siempre que tengan el mismo nivel político } \\
\text { y administrativo. Estos procesos deberán contar con el aval del gobierno nacional } \\
\text { como rector de la política internacional. }\end{array}$ \\
\hline REGIONALIZACIÓN & $\begin{array}{l}\text { El ordenamiento territorial promoverá el establecimiento de Regiones } \\
\text { Administrativas y de Planificación como marcos de relaciones geográficas, } \\
\text { económicas, culturales y funcionales, a partir de ecosistemas bióticos y biofísicos, } \\
\text { de identidades culturales locales, de equipamientos e infraestructuras económicas y } \\
\text { productivas y de relaciones entre las formas de vida rural y urbana, en el que se } \\
\text { desarrolla la sociedad colombiana y hacia donde debe tender el modelo de Estado } \\
\text { republicano unitario. En tal sentido, la creación y el desarrollo de Regiones } \\
\text { Administrativas y de Planificación y la regionalización de competencias y recursos } \\
\text { públicos se enmarcan en una visión del desarrollo hacia la complementariedad, con } \\
\text { el fin de fortalecer la unidad nacional. }\end{array}$ \\
\hline SOSTENIBILIDAD & $\begin{array}{l}\text { El ordenamiento territorial conciliará el crecimiento económico, la sostenibilidad } \\
\text { fiscal, la equidad social y la sostenibilidad ambiental, para garantizar adecuadas } \\
\text { condiciones de vida de la población. }\end{array}$ \\
\hline PARTICIPACIÓN & $\begin{array}{l}\text { La política de ordenamiento territorial promoverá la participación, concertación y } \\
\text { cooperación para que los ciudadanos tomen parte activa en las decisiones que inciden } \\
\text { en la orientación y organización territorial. }\end{array}$ \\
\hline $\begin{array}{l}\text { SOLIDARIDAD Y } \\
\text { EQUIDAD TERRITORIAL }\end{array}$ & $\begin{array}{l}\text { Con el fin de contribuir al desarrollo armónico del territorio colombiano, la Nación, } \\
\text { las entidades territoriales y las figuras de integración territorial de mayor capacidad } \\
\text { política y administrativa, económica y fiscal, apoyarán aquellas entidades de menor } \\
\text { desarrollo relativo, en procura de garantizar el acceso equitativo a las oportunidades } \\
\text { y beneficios del desarrollo, para elevar la calidad de vida de la población. }\end{array}$ \\
\hline DIVERSIDAD & $\begin{array}{l}\text { El ordenamiento territorial reconoce las diferencias geográficas, institucionales, } \\
\text { económicas, sociales, étnicas y culturales del país, como fundamento de la unidad e } \\
\text { identidad nacional, la convivencia pacífica y la dignidad humana. }\end{array}$ \\
\hline
\end{tabular}

$250 \mid$ Franz Gutiérrez Rey 


\begin{tabular}{|c|c|}
\hline PRINCIPIO & TESIS \\
\hline $\begin{array}{l}\text { GRADUALIDAD } \\
\text { Y FLEXIBILIDAD }\end{array}$ & $\begin{array}{l}\text { El ordenamiento territorial reconocerá la heterogeneidad de las comunidades y } \\
\text { geografías del país y se ajustará a las diferencias relativas de desarrollo entre las } \\
\text { diversas regiones (porciones del territorio) que lo integran. Las entidades e instancias } \\
\text { de integración territorial se adaptarán progresivamente, para lo cual podrán } \\
\text { asignárseles las competencias y recursos que les permitan aumentar su capacidad } \\
\text { planificadora, administrativa y de gestión. }\end{array}$ \\
\hline PROSPECTIVA & $\begin{array}{l}\text { El ordenamiento territorial estará orientado por una visión compartida de país a } \\
\text { largo plazo, con propósitos estratégicos que guíen el tipo de organización territorial } \\
\text { requerida. }\end{array}$ \\
\hline PAZ Y CONVIVENCIA & $\begin{array}{l}\text { El ordenamiento territorial promoverá y reconocerá los esfuerzos de convivencia } \\
\text { pacífica en el territorio e impulsará políticas y programas de desarrollo para la } \\
\text { construcción de la paz, el fortalecimiento del tejido social y la legitimidad del } \\
\text { Estado. }\end{array}$ \\
\hline ASOCIATIVIDAD & $\begin{array}{l}\text { El ordenamiento territorial propiciará la formación de asociaciones entre las entidades } \\
\text { territoriales e instancias de integración territorial para producir economías de escala, } \\
\text { generar sinergias y alianzas competitivas, para la consecución de objetivos de } \\
\text { desarrollo económico y territorial comunes. }\end{array}$ \\
\hline $\begin{array}{l}\text { RESPONSABILIDAD Y } \\
\text { TRANSPARENCIA }\end{array}$ & $\begin{array}{l}\text { Las autoridades del nivel nacional y territorial promoverán de manera activa el } \\
\text { control social de la gestión pública, incorporando ejercicios participativos en la } \\
\text { planeación, ejecución y rendición final de cuentas, como principio de responsabilidad } \\
\text { política y administrativa de los asuntos públicos. }\end{array}$ \\
\hline $\begin{array}{l}\text { EQUIDAD SOCIAL Y } \\
\text { EQUILIBRIO } \\
\text { TERRITORIAL }\end{array}$ & $\begin{array}{l}\text { La Nación y las entidades territoriales propiciarán el acceso equitativo de todos los } \\
\text { habitantes del territorio colombiano a las oportunidades y beneficios del desarrollo, } \\
\text { buscando reducir los desequilibrios sociales, económicos y ambientales entre ellas. } \\
\text { Así mismo, los procesos de ordenamiento procurarán el desarrollo equilibrado entre } \\
\text { áreas urbanas, rurales y costeras de estas en relación con la región. }\end{array}$ \\
\hline $\begin{array}{l}\text { ECONOMÍA Y } \\
\text { BUEN GOBIERNO }\end{array}$ & $\begin{array}{l}\text { La organización territorial del Estado deberá garantizar la autosostenibilidad } \\
\text { económica, el saneamiento fiscal y la profesionalización de las administraciones } \\
\text { territoriales, por lo que se promoverán mecanismos asociativos que privilegien la } \\
\text { reducción del gasto y el buen gobierno en su conformación y funcionamiento. La ley } \\
\text { determinará los principios de economía y buen gobierno mínimos que deberán } \\
\text { garantizar los departamentos, los distritos, los municipios, las áreas metropolitanas, } \\
\text { sus descentralizadas, así como cualquiera de las diferentes alternativas de asociación, } \\
\text { contratos o convenios plan o delegaciones previstas en la presente ley. }\end{array}$ \\
\hline
\end{tabular}

Fuente: Proyecto de Ley Orgánica, N. ${ }^{\circ} 058$, 2010, República de Colombia.

A pesar de que la propuesta de Ley es, en mi opinión, un buen resumen de experiencias y discusiones, es necesario seguir trabajando en el afinamiento y profundización de temas como el desarrollo sostenible y el buen gobierno (gobernanza), y en la inclusión de temas como la cohesión territorial, por el significado de sus contenidos y aportación en la organización territorial.

\section{Desarrollo Sostenible y Ordenamiento Territorial}

El desarrollo sostenible, en la concepción de equilibrio entre lo ambiental, lo social, lo económico y lo territorial, determina una nueva postura ética y política frente a la noción de desarrollo del país; esta visión va mucho más allá de la "sostenibilidad clorofila", concepción 
actual que prima en el desarrollo territorial y que no hace parte de la ideología de la atmósfera política del desarrollo sostenible actual, y, por otra parte, implica una construcción a partir de los elementos que empiezan a permear el país en el desarrollo y aplicación de las políticas ambientales sostenibles, así estén en contradicción en la práctica.

La más conocida definición de desarrollo sostenible es la presentada en el Informe de la Comisión Mundial sobre el Medio Ambiente y Desarrollo, "Comisión Brundtland": Nuestro Futuro Común, que en 1987 lo definió como el desarrollo que asegura la satisfacción de las necesidades del presente sin comprometer la capacidad de las futuras generaciones para atender a sus propias necesidades.

La satisfacción de las necesidades del futuro depende de cuánto equilibrio se logre entre los objetivos (necesidades) sociales, económicos, ambientales y territoriales en las decisiones que se toman ahora. Esta es la urgencia manifiesta, a pesar de que los objetivos parecen estar en conflicto con el modelo territorial actual (economía de mercado).

Las circunstancias actuales de la planificación territorial en Colombia no generan ni permiten aún las condiciones adecuadas para que el desarrollo sostenible se establezca como el fin o la meta de la planificación, la ordenación y la gestión territorial.

Si la planeación y el ordenamiento territorial (OT) se conciben como una política de Estado y un proceso planificado de naturaleza política, técnica y administrativa, cuyo objeto central es organizar, armonizar y administrar la ocupación y uso del espacio, de modo que se contribuya al desarrollo humano ecológicamente sostenible, espacialmente armónico y socialmente justo, es evidente que en el OT confluyen las políticas ambientales, las políticas de desarrollo regional, espacial o territorial y las políticas de desarrollo social y cultural (Massiris, 2000). Por esto el ordenamiento territorial y la ordenación del territorio son parte intrínseca del desarrollo sostenible.

Visto así, en el OT el espacio pierde el carácter pasivo propio de la visión sectorial, para convertirse en estructurante de los objetivos, las políticas y las acciones públicas y privadas, tanto sectoriales como territoriales. Se trata, en este caso, de articular los objetivos económicos, sociales, ambientales y administrativos con el territorio, racionalizar las actuaciones sobre este y orientar previsoriamente su desarrollo y aprovechamiento sostenible, basado, especialmente, en estrategias de uso, ocupación y manejo del territorio, y de desarrollo territorial (Ortiz y Massiris, 1993).

De esta manera, el ordenamiento territorial se convierte en el instrumento clave que forma parte de la política de Estado sobre el desarrollo sostenible; a la vez que es un proceso político, en la medida que involucra la toma de decisiones concertadas de los actores

252 Franz Gutiérrez Rey 
sociales, económicos, políticos y técnicos, para la ocupación ordenada y uso sostenible del territorio. Así mismo, es un proceso técnico-administrativo, porque orienta la regulación y promoción de la localización y desarrollo de los asentamientos humanos, de las actividades económicas, sociales y el desarrollo físico espacial (Instituto Geográfico Agustín Codazzi, 1996, 1997a, 1997b; Banco Internacional de Desarrollo, 1999; Massiris, 2006; Secretaría de Desarrollo Social, 2009).

La Ley Orgánica de Ordenamiento Territorial (LOOT), por principio, debería resolver el anterior planteamiento de desarrollo sostenible, al igual que la gestión y la armonización de la planificación territorial en los diferentes niveles político-administrativos ${ }^{6} \mathrm{y}$ escalares $^{7}$, para no tener en el escenario una serie de decisiones desintegradas (división del territorio en fragmentos), disfuncionales (no cumplen una función armónica, complementaria o de subsidiariedad) y desarticuladas (desencajadas del lugar que le corresponde), entre los diferentes entes político-administrativos del país.

Sería entonces una utopía concebir el desarrollo sostenible sin un plan que lo oriente, sin unos principios rectores que lo guíen y unos valores que prioricen y privilegien aspectos, asegurando que: la participación ciudadana esté en los procesos de diagnóstico, evaluación, prospección, toma de decisiones y gestión; el interés general efectivamente prime sobre el particular, permitiendo mayores niveles de sostenibilidad; los usos del suelo estén de acuerdo con su aptitud, vocación, funcionalidad ecológica (uso óptimo del territorio); los planes de desarrollo, al ser de corto plazo, se orienten a construir la imagen objetivo de los planes de ordenamiento territorial en el largo plazo, garantizando de paso la continuidad de la gestión administrativa local; los procesos ecológicos y las funciones ecosistémicas de valor estratégico para la población puedan ser sujetas de regímenes especiales inviolables (protección socioambiental), entre otros más.

Finalmente, de acuerdo con Pérez (2009), el desarrollo sostenible podría materializar un modelo deseable y viable para el país, lo que significa un cambio en nuestros métodos tradicionales de intervención en el territorio.

\section{Gobernanza territorial}

La gobernanza territorial, propuesta como nuevo enfoque, se entiende de dos maneras: en primer lugar, como los procesos que permiten implementar regulaciones económicas, sociales, ambientales y políticas aceptadas por los

Urbano, rural, municipal, provincial, departamental, "subregional y regional" (Pujadas, 1998).

7 Escalas en las cuales se ordena el territorio, con metodologías, procesos, instrumentos y alcances distintos. También son escalas en donde se puede leer la sostenibilidad, la coherencia y la armonía de un proyecto de sociedad y de territorio. Para Colombia, la no existencia de la LOOT hace que en la Ley 388 de 1997 se declare inexequible la posibilidad de que los departamentos y áreas metropolitanas formulasen sus respectivos planes. 
habitantes; en las Ciencias Sociales, el concepto se refiere no a una capacidad, sino a un proceso o a un conjunto de interacciones, y considera lo que de ellas resulta (Launay, 2007; 2008). "La gobernanza se refiere a los procesos de acción colectiva que organizan la interacción entre los actores, la dinámica de los procesos y las reglas de juego con las cuales una sociedad toma sus decisiones, y determina su conducta" (IDRC, 2004). En segundo lugar, como el conjunto de herramientas institucionales, consistente en la promoción de una mejor transparencia en los asuntos públicos, de una más efectiva descentralización y de un fortalecimiento de los mecanismos de participación ciudadana (modelos democráticos existentes en Europa o en América del Norte y Banco Mundial); acá cabe en particular el concepto de la gobernanza pública o manera de gobernar (capacidad), que se propone como objetivo el logro de un desarrollo económico, social e institucional duradero, promoviendo un sano equilibrio entre el Estado, la sociedad civil y la economía (DRAE, 2010; Farinos, 2007). El concepto de "institucionalidad eficiente y eficaz ("con músculos' o 'con dientes' coercitivos)" para la gestión legislativa y el control político del ordenamiento territorial también cabría aquí (COT, 1993; Eljash, 2010). Tabla 2 -Orgánico-.

Los dos enfoques de la gobernanza son necesarios y no excluyentes en Colombia. De un lado, existe la necesidad de modernizar las prácticas de gobierno dictadas en general por los principios de la Cooperación Internacional (aplicación "institucional" o "legal" de la gobernanza bajo criterios predeterminados). Por otro lado, una visión de una gobernanza según los contextos políticos y sociales específicos es necesaria. Por tal razón, la propuesta es entonces la aplicación en Colombia de un concepto de "gobernanza diferenciada", en el sentido de la presencia diferenciada del Estado (Launay, 2008).

Sin embargo, no se ha contemplado, tal vez, otras maneras de entender la gobernanza que podrían adaptarse a los diferenciales grados de centralización política e integración territorial y social con los que funcionan el Estado y la ciudadanía en Colombia. (Launay, 2007).

La existencia de guerrillas, narcotráfico, paramilitares, neoparamilitares y delincuencia organizada perturba sensiblemente la gobernabilidad y, para el caso, la gobernanza; se debe tener presente que en los procesos de paz no se han considerado los aspectos territoriales, como tampoco el tema de la organización político-administrativa del país (regionalización).

\section{Cohesión territorial}

La cohesión territorial es fundamental; es definida como un principio para las actuaciones públicas encaminadas al logro de objetivos como: crear lazos de unión entre los miembros de una comunidad territorial (cohesión social) y favorecer el acceso equitativo de estos a 
servicios y equipamientos (equidad/ justicia espacial); configurar un auténtico proyecto territorial común (identidad, arraigo y pertenencia), partiendo del respeto a la diversidad y las particularidades; articular y comunicar las distintas partes del territorio, y romper las actuales tendencias hacia la polarización y desigualdad entre territorios, aprovechando las fortalezas y rasgos inherentes de cada uno de ellos. Se trata, además, de buscar la cohesión o coherencia interna del territorio, así como la mejor conectividad de dicho territorio con otros territorios vecinos (Fernández et al., 2009).

En este sentido, la cohesión territorial es un principio para las actuaciones públicas encaminadas al desarrollo territorial, que comprende tres elementos esenciales: la articulación física entre las partes del territorio; la equidad territorial, entendida como la igualdad de oportunidades de prestación de servicios públicos, equipamientos e infraestructuras para alcanzar el desarrollo de la persona en todas las partes de un territorio, y la identificación de la comunidad que puebla un territorio con un proyecto de vida en común (campo de los sentimientos: pertenencia, arraigo e identidad) (CESU, 2006; Fernández et al, 2009; Pascual, 2009, y Farinós, 2009).

El concepto de la identificación de la comunidad que puebla un territorio con un proyecto de vida en común es, en Colombia, fundamental y de fácil entendimiento, por cuanto es un ejercicio cotidiano en las regiones culturales del país ${ }^{8}$, pero aún no es reconocido por el Gobierno en la división político administrativa de tipo centralista, que no permite la conformación de estas regiones a partir de porciones departamentales; de aquí la gran importancia de enfocar los procesos de regionalización en la LOOT desde esta concepción, que, entre otras, es una política de paz. La gran dificultad de implementar la cohesión social radica en que el régimen de las elecciones sigue siendo básicamente preconstituyente, y la democracia, el sistema político y el "régimen" se constituyen con base en el elemento electoral (legitimidad) y no en el territorial.

La cohesión aporta una visión espacial o territorial a los otros conceptos, trasladando todas aquellas cuestiones que antes se presentaban bajo un prisma puramente social (igualdad, equidad, solidaridad, protección social) a un enfoque territorial (solidaridad y justicia territoriales). Así mismo, la idea de cohesión territorial no solo abarca cuestiones de equidad o solidaridad interterritoriales (lo cual no sería poco), sino también objetivos de protección ambiental y sostenibilidad y mecanismos de integración/coordinación de las distintas políticas sectoriales con incidencia territorial (Fernández et al, 2009).

8 Costeños, paisas, llaneros, santandereanos, pastusos, opitas, amazonidas, cundiboyacences, vallunos, chocoanos, etc. Las comunidades indígenas colombianas no participan de la ordenación del territorio por mandato de la Corte Constitucional (Sentencia C795 de 2000), estas cuentan con proyectos de vida, tienen cohesión social y equidad/justicia espacial en su territorio, siendo diferenciados en relación con los territorios circunvecinos de la economía de mercado. 
Eljach (2010) plantea que, en la realidad, "en Colombia hay mucho más territorio que Estado; poco Estado y mucho gobierno; más Presidente que Gobierno", y se ha continuado la línea de centralismo político con un poco de descentralización. En la actualidad, el nuevo régimen político constitucional (partidos, periodos, bancadas, reelección) especialmente en cuanto a partidos políticos y circuns-cripciones, hace más notoria la falta de legislación actualizada sobre la distribución espacial del poder; aspecto clave, a mi parecer, para el desarrollo de una política de cohesión territorial nacional.

\section{Conclusiones}

A diecinueve años de proclamada la Constitución Política de Colombia (1991), aún no ha sido posible promulgar la LOOT, en razón a tres factores: voluntad política, interés en la dimensión regional del ordenamiento territorial y el gran número de normas sobre la materia, que implica en muchas ocasiones desconocimiento del tema.

Ante el vacío legislativo en materia de organización territorial en algunos asuntos trascendentales, se siguen aplicando leyes preconstituyentes; la Corte Constitucional, en sus fallos, ha trazado los lineamientos; se aplica el principio de la precaución (internacionalización de las relaciones) y se han aprobado leyes ordinarias dispersas en diversos temas de ordenamiento territorial y ambiental.

La jurisprudencia ha permitido que la legislación sobre asuntos territoriales se expida fragmentariamente y no en una única LOOT, por lo que se deduce que no es conveniente ni oportuno reunir todo el régimen jurídico de la organización territorial del Estado en una única LOOT.

En la propuesta de LOOT (2010) se encuentran avances significativos en materia de visión del país, del desarrollo sostenible y de la ordenación del territorio. El proyecto recoge una larga experiencia y discusiones en temas como: organización del Estado, participación ciudadana, convivencia pacífica, convivencia de un orden justo y crecimiento socioeconómico equitativo; plantea alianzas estratégicas y promueve la capacidad de negociación entre la Nación y las entidades territoriales través de propósitos estratégicos, validando los principios rectores del ejercicio de competencias propuestos en la CPC, pero ya no como del OT en general; involucra el concepto de "buen gobierno" y respecto a la Comisión de Ordenamiento Territorial (COT), y busca su consolidación como órgano meramente técnico y de consulta del Gobierno y el Congreso.

El desarrollo sostenible, actualmente, determina una nueva postura frente a la noción de desarrollo del país (nueva ideología de la atmósfera política). Se busca que el ordenamiento territorial y la ordenación del territorio sean parte intrínseca de este. De esta manera, el OT es el instrumento clave que forma parte de la política de Estado sobre el desarrollo sostenible, a la vez que es un proceso político. El desarrollo sostenible

256 Franz Gutiérrez Rey 
podría materializar un modelo deseable y viable para el país, lo que significa un cambio en nuestros métodos tradicionales de intervención en el territorio.

La Ley Orgánica de Ordenamiento Territorial (LOOT), por principio, debería resolver el anterior planteamiento de desarrollo sostenible, al igual que la gestión y la armonización de la planificación territorial en los diferentes niveles político-administrativos y escalares, para no tener en el escenario una serie de decisiones desintegradas, disfuncionales y desarticuladas, entre los diferentes entes político-administrativos del país.

Sería una utopía concebir el desarrollo sostenible sin un plan que lo oriente, sin unos principios rectores que lo guíen y unos valores que prioricen y privilegien los aspectos considerados en su propuesta; lo anterior podrá lograrse en la LOOT o en una Ley ordinaria sobre el tema.

Es necesario seguir trabajando en el afinamiento, profundización y aplicación específica del DS al país, junto con temas como el buen gobierno (la gobernanza) y la cohesión social y territorial.

La Gobernanza se entiende como los procesos que permiten la implementación de regulaciones económicas, sociales, ambientales y políticas, aceptadas por los habitantes, y como el conjunto de herramientas institucionales, consistente en la promoción de una mejor transparencia en los asuntos públicos, de una más efectiva descentralización y de un fortalecimiento de los mecanismos de participación ciudadana. Los dos enfoques son necesarios y no excluyentes para Colombia. La propuesta es, entonces, aplicar en Colombia un concepto de "gobernanza diferenciada", en el sentido de la presencia diferenciada del Estado. Sin embargo, tal vez no se han contemplado otras maneras de entender la gobernanza que podrían adaptarse a los diferentes grados de centralización política e integración territorial y social con los que funcionan el Estado y la ciudadanía en Colombia.

La importancia de la cohesión territorial radica en su aporte de la visión espacial o territorial a los conceptos que se presentan normalmente dentro de un prisma social (igualdad, equidad, solidaridad, protección social) a un enfoque territorial (solidaridad y justicia territoriales). Así mismo, la idea de cohesión territorial abarca cuestiones de equidad o solidaridad interterritorial, objetivos de protección ambiental y sostenibilidad, y mecanismos de integración/coordinación de las distintas políticas sectoriales con incidencia territorial.

Se debe tener presente que para los procesos de paz en el país no se han considerado los aspectos territoriales, ni los temas de la organización políticoadministrativa (regionalización), del desarrollo sostenible, de la gobernanza diferenciada y de la cohesión, claves en la resolución de los conflictos y gestores de un nuevo país. 


\section{Literatura citada}

Banco Internacional de Desarrollo (BID). (1999). Reunión del Grupo Consultivo para la reconstrucción y la transformación de Centroamérica. Memorias. Washington, D.C.: División de Administración de Recursos Naturales y Medio Ambiente. Editores A. Uribe, H. Franklin.

Barrios de Caputo, H. (1996). "Desarrollo sostenible y ecoeficiencia para enfrentar el siglo xxI”. Revista Gestión, 2: 50-54. Barranquilla, Colombia: Universidad del Norte.

Carrión Barrero, G. A. (2008). "Debilidades del nivel regional en el Ordenamiento Territorial colombiano. Aproximación desde la normatividad política administrativa y de usos del suelo". Arquitectura, Ciudad y Entorno (ACE). Bogotá: Disponible en http://upcommons.upc.edu/revistes/ bitstream/2099/5648/ 1/9_GUSTAVO-CARRION.pdf

Centro de Estudios Universitarios Superiores (CESU). (2006). Gobernabilidad y gobernanza de los territorios en América Latina. Memorias. Cochabamba, Bolivia: Universidad Mayor de San Simón de Cochabamba. Cooperación Regional Francesa IFEA, IRD. Congreso Internacional, 19, 20, 21 septiembre.

Departamento Nacional de Planeación (DNP). (2007). Proyecto de Ley Orgánica de Ordenamiento Territorial. Comentarios y recomendaciones respecto al proyecto de Ley Orgánica de Ordenamiento Territorial, Mesa de Trabajo $N^{\circ}$. 1. Bogotá: Dirección de Desarrollo Territorial Sostenible (DDTS), Subdirección de Ordenamiento y Desarrollo Territorial (SODT).

Departamento Nacional de Planeación (DNP). (2010). Recopilación de preguntas frecuentes. Bogotá: Dirección de Desarrollo Territorial Sostenible (DTTS). Subdirección de Ordenamiento y Desarrollo Territorial, Finanzas Públicas Territoriales, Grupo de Análisis al Financiamiento del Desarrollo Territorial y Grupo de Gestión Pública Territorial.

Eljach Pacheco, G. (2007). Plataforma legislativa integral sobre Ordenamiento Territorial. Bogotá: Universidad de los Andes (UA). Foro Descentralización y Ordenamiento Territorial: Retos y Perspectivas para el 2019. Disponible enhttp:// www.dnp.gov.co/PortalWeb/Portals/0/archivos/documentos/2019/Documentos/ Gregorio_Eljach_UniAndes(31_oct_07).pdf

Eljach Pacheco, G. (2010). Mapa legislativo del Ordenamiento Territorial colombiano. Ciclo de Conferencias Estatutarias de Posesión Miembros de Número de la Sociedad Geográfica de Colombia (SOGEOCOL). Bogotá: Instituto Geográfico Agustín Codazzi (IGAC), Universidad Pedagógica Tecnológica de Colombia (UPTC), Programa de Estudios de Posgrado en Geografía (EPG). 
Farinós, J. y Romero, J. (eds.). (2007). Territorialidad y buen gobierno para el Desarrollo Sostenible. Nuevos principios y nuevas politicas del espacio europeo. Valencia, España: Universidad de Valencia. PUV. Colección: Desarrollo Territorial. Serie Estudios y Documentos 2.

Farinós, J.; Romero, J.; Salom J. (eds). (2009). Cohesión e inteligencia territorial. Dinámicas y procesos para una mejor planificación y toma de decisiones. Valencia, España: Universidad de Valencia. PUV. Colección: Desarrollo Territorial. Serie Estudios y Documentos 7.

Fernández Tabales, A.; Pedregal Mateos, B.; Rodríguez Mateos, J. C.; Pita López, M. ${ }^{\text {a }}$ F. y Zoido Naranjo, F. (2009). El concepto de cohesión territorial. Escalas de aplicación, sistemas de medición y políticas derivadas. Boletín de la Asociación de Geógrafos Españoles (AGE), N. ${ }^{\circ}$ 50. Sevilla, España: Universidad de Sevilla, Facultad de Geografía e Historia, Departamento de Geografía Física y Análisis Geográfico Regional.

Ferrando Badía, J. (2005). "El Estado Unitario". Revista de Estudios Políticos (REP), mayo-agosto, No. 195. España: Disponible enhttp://www.cepc.es/rap/ Publicaciones/Revistas/2/REP_195-196_013.pdf

García Henao, L. (2003). "Teoría del Desarrollo Sostenible y Legislación Ambiental Colombiana, una reflexión cultural”. Revista de Derecho, 20: 198-215. Barranquilla, Colombia: Universidad del Norte.

Guío Camargo, R. E. (2009). Función social y ecológica de la propiedad. Características y alcances. Bogotá: Universidad Católica de Colombia, Estudios en Derecho y Gobierno.

Instituto Geográfico Agustín Codazzi (IGAC). (1996). Guía Metodológica para la formulación del Plan de Ordenamiento Territorial Urbano. Bogotá: Editorial Linotipia Bolívar.

Instituto Geográfico Agustín Codazzi (IGAC). (1997a). Bases conceptuales y guía metodológica para la formulación del Plan de Ordenamiento Territorial Departamental. Bogotá: Linotipia Bolívar.

Instituto Geográfico Agustín Codazzi (IGAC). (1997b). Guía metodológica para la formulación del Plan de Ordenamiento Municipal. Santafé de Bogotá: Linotipia Bolívar.

International Development Research Center (IDRC). (2004). Gobernanza: Hacia un concepto. Taller de trabajo. Montevideo: Grupo Latinoamericano de la Oficina Regional para América Latina y el Caribe.

Ladino Orjuela, W. H. (2008). Organización del Estado colombiano y formas organizativas del Estado a nivel territorial. Bogotá: Escuela Superior de Administración Pública (ESAP), Programa de Administración Pública Territorial.

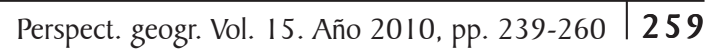


Launay, C. y Bolívar, I. (2007). "Lenguajes políticos globales y desafíos de la gobernanza en Colombia". Revista Controversia, N. ${ }^{\circ}$ 188. Bogotá: Centro de Investigación y Educación Popular (CINEP).

Launay, C. (2008). Ambigüedades y desafíos de la gobernanza en Colombia, Memorias. Bogotá: Centro de Investigación y Educación Popular (CINEP). Congreso Colombiano de Ciencias Políticas, Proyecto: Gobernanza y Civilidad.

Martínez Toro, P. M. (2005). Ordenamiento Territorial y Desarrollo Sostenible, Memorias. Cali, Colombia: Universidad del Valle, Departamento de Geografía. II Encuentro de Hábitat Sostenible, 9 al 12 de noviembre.

Massiris Cabeza, Á. (2000). "Ordenamiento Territorial y procesos de construcción regional”. Revista Credencial Historia. Bogotá: Biblioteca Luis Ángel Arango, del Banco de la República. Disponible en: http://www.lablaa.org/blaavirtual/ geografia/masir/presen.htm

Massiris Cabeza, Á. (2006). Políticas latinoamericanas de ordenamiento territorial: realidad y desafios. Tunja, Colombia: Universidad Pedagógica y Tecnológica de Colombia (Uptc). Imprenta y Publicaciones Uptc, Colección Investigación Uptc N. ${ }^{\circ} 4$.

Ortiz, A. P.; Massiris Cabeza, Á. (1993). "Bases para el Ordenamiento del Pacífico Colombiano". En: El Pacífico Colombiano. Tomo II. Bogotá: Fondo Eléctrico Nacional (FEN).

Pascual Esteve, J. M. ${ }^{a}$ y Pascual Guiteras, J. (2009). Cohesión Social y Gobernanza Democrática: para unas regiones y ciudades más inclusivas. Andalucía, España: América-Europa de Regiones y Ciudades (AERYC). Consejería de Gobernación. Real Academia Española. 2001. DRAE. Disponible en http:// www.rae.es/rae.html.

Rodríguez, G. A. (2004). La función ecológica de la propiedad. Documento Parcial. Bogotá: Universidad del Rosario. Disponible en http://www.urosario.edu.co/ fase $1 /$ jurisprudencia/

Secretaría de Desarrollo Social (SEDESOL). (2009). Metodología para la elaboración de Programas Municipales de Ordenamiento Territorial. Estados Unidos Mexicanos, México D. F.: Gobierno Federal.

Vargas Lleras, G. (2010). Exposición de motivos proyecto de Ley Orgánica de Ordenamiento Territorial. Bogotá: Ministerio del Interior y de Justicia.

Recepción: 23 de octubre de 2010

Aprobación: 22 de noviembre de 2010

260| Franz Gutiérrez Rey 